\title{
Editorial
}

\section{Necessity brought it back, Sophistication should make it stay!}

\author{
Girinivasan Chellamuthu ${ }^{\circledR 1}$, , Sathish Muthu $^{\circledR 1}$, Manish Khanna ${ }^{\circledR 2,3}$ \\ ${ }^{1}$ Orthopaedic Research Group, Coimbatore, Tamil Nadu, India \\ ${ }^{2}$ Dept. of Orthopaedics, Prasad Institute of Medical Science(PIMS) \& Hospital, Lucknow, Uttar Pradesh, India \\ ${ }^{3}$ Dept. of Orthopaedics, Apley Orthopaedic Centre, Lucknow, Uttar Pradesh, India
}

\section{A R T I C L E I N F O}

Article history:

Received 12-12-2020

Accepted 22-12-2020

Available online 15-01-2021

\begin{abstract}
This is an Open Access (OA) journal, and articles are distributed under the terms of the Creative Commons Attribution-NonCommercial-ShareAlike 4.0 License, which allows others to remix, tweak, and build upon the work non-commercially, as long as appropriate credit is given and the new creations are licensed under the identical terms.
\end{abstract}

For reprints contact: reprint@ipinnovative.com
2020 was a reality check for the health care sector across the world. COVID encumbered and exhausted the health care system. Lives were at stake all at once. We were forced to get adapted rapidly to maintain homeostasis in health care. One of the few positives of such rapid adaptation was the acceptance and widespread use of Telemedicine.

From transferring electrocardiographic data over the telephone in the early $20^{\text {th }}$ century ${ }^{1}$ to conducting the first telesurgery in $2001,{ }^{2}$ the field has grown leaps and bounds embracing the cutting-edge technology and oddities of medicine.

'Shifting technology, finding the right talent, finding the right product set and strategy-that's all doable, not easy, but doable. Hardest is the cultural transformation in businesses that have very deep legacy and cultural roots" James Bilefield, McKinsey

Telemedicine with all its merits has always been there. For example, a pilot study on a dedicated telehealth HIPPA compliant mobile platform in the National University Hospital of Singapore reported encouraging results in 2014. ${ }^{3}$ However, there were no prolific takers for some reasons particularly in countries like India. For all of us used to the out-patient department, where we assess the patients with all our eyes and ears, alleviate their agony not

\footnotetext{
* Corresponding author.

E-mail address: girichellamuthu@ orthopaedicresearchgroup.com (G. Chellamuthu).
}

only by dispensing drugs but with our emotional connection and soothing words, telemedicine might not be entirely satisfactory on the first thought. And phrases in conventional medical teaching like "healing touch is rather important" might even seem to criminalize telemedicine.

However, objectively looking beyond the initial hesitations, research on the effectiveness of telemedicine in Orthopaedics and Rehabilitation has always been encouraging. ${ }^{4}$ Some demerits like first-hand clinical examination and slight risk of undertreatment while using telemedicine are far outweighed by the potential benefits it offers. It is convenient, reduces appointment delays, travel time, travel costs, and time off work. These, along with the good telemedical care shall provide high patient satisfaction. This increases the patient compliance to treatment.

With most of these benefits being already known, COVID, at its full throttle, has forced us to drop down initial hesitations and embrace telemedicine. Technological advancements like cheap internet and easy availability of gadgets have enhanced the milieu for telemedicine making it a possibility even in the rural parts of the country.

"When there is a possibility of such a good system, why not perfect it and use it?" As we find a way out of COVID through vaccines, this is the question that would linger in the minds of some of us and most of the patients. 
The tertiary care trauma center where we practice carters 6 districts around us. A patient with a floating knee who came for a one month follow up review had to spend two months of his salary for transport and wait half a day to be reviewed with X-rays. The sheer charge of transport here essentially nullified the free care provided by the Government. The apprehension of the treating surgeon like missing early signs of infection and missing important sessions of physiotherapy leading to stiffness should also not be ignored.

The perfection of telemedicine should aim to address such issues. The highest standard of patient care should be the core of telemedicine as it takes patient-transport off the context of patient care. Setting up of dedicated departments to telemedicine should be done. This, besides emphasizing our commitment will help zooming into and analyzing the hurdles.

1. Outreach telemedicine centers can be tried. This can exclusive or tie-ups with local physiotherapy units or general physicians which shall improve patient and physician satisfaction in telemedicine.

2. Outreach imaging centers can be listed out.

3. Institutional level protocols on designating a patient as fit for telemedicine follow-ups, for example 'after a second post-operative review' - should be drawn.

4. Guidelines on tests for objective assessment of functional outcomes and patient-related outcome measures during the telemedicine review can be listed out.

5. Outreach personnel training for telemedicine can be started.

6. Digital reforms such as the development of new mobile applications and virtual platforms can be tried or personalizing existing platforms like Skype or Zoom can be attempted

Telemedicine implementation reduces the load on the hospitals equally as it does on the patients. It speeds up the services and reduces the crowd. It will help in directing valuable resources on more important tasks. The sophistication that telemedicine offers should be valued. Legislations and measures to improvise telemedicine will dawn a new area of safe and cost-effective virtual consultations in the post COVID world.

\section{Conflict of Interest}

The authors have no conflict of interest.

\section{References}

1. World Health Organization, editor. Telemedicine: opportunities and developments in member states: report on the second Global survey on eHealth. Geneva, Switzerland: World Health Organization; 2010.

2. Choi PJ, Oskouian RJ, Tubbs RS. Telesurgery: Past, Present, and Future. . Cureus. 2020;10(5). Available from: https://www.ncbi.nlm. nih.gov/pmc/articles/PMC6067812/.

3. Daruwalla ZJ, Wong KL, Thambiah J. The Application of Telemedicine in Orthopedic Surgery in Singapore: A Pilot Study on a Secure, Mobile Telehealth Application and Messaging Platform. JMIR mHealth uHealth. 2014;2(2):e28. Available from: https://www.ncbi.nlm.nih.gov/ pmc. dor: $102106 / \mathrm{mhealth} 3303$.

4. Haider Z, Aweid B, Subramanian P, Iranpour F. Telemedicine in orthopaedics and its potential applications during COVID-19 and beyond: A systematic review. $J$ Telemedicine Telecare. 2020 .01:-10.

\section{Author biography}

Girinivasan Chellamuthu, Research Associate (1) https://orcid.org/00000001-5800-714X

Sathish Muthu, Research Associate (i) https://orcid.org/0000-0002-71434354

Manish Khanna, Professor and HOD (1) https://orcid.org/0000-00022890-869X

Cite this article: Chellamuthu G, Muthu S, Khanna M. Necessity brought it back, Sophistication should make it stay!. IP Int J Orthop Rheumatol 2020;6(2):39-40. 